\title{
Manufacturers' Emergency Procurement Strategies under Supply Disruption and Competition Based on Scenario Analysis
}

\author{
Xinjun $\mathrm{Li}^{1}$ and Xiaonan Zhang ${ }^{2}$ \\ ${ }^{1}$ School of Economic and Management, Yantai University, Yantai 264005, China \\ ${ }^{2}$ School of Economic and Management, Yantai University, Yantai 264005, China \\ ${ }^{1}$ E-mail :lixinjun101@163.com, ${ }^{2}$ E-mail :zhangxiaonan6585304@126.com
}

\begin{abstract}
Emergency procurement strategies have attracted significant attention from academicians and practitioners with the increase of supply disruptions in the past two decades. We study a manufacturer's contingent sourcing strategies under supply disruption and competition using Stackelberg game. We investigate a two-stage supply chain consisting of two competing manufacturers and two suppliers, where the wholesale prices offered by the two suppliers are different. Supplier 1 is unreliable and cheap, while supplier 2 is reliable and expensive, and moreover, supplier 2 has capacity limits. Manufacturer A uses a dual-sourcing, manufacturer $B$ uses a single-sourcing. According to two manufacturers' order sequence, we established two manufacturers' expected profit function under three scenarios. We obtain the optimal order quantities and expected profits of the two manufacturers in different scenarios, and show that supply disruption and procurement time have effect on the manufacturer's purchasing decisions.
\end{abstract}

Keywords: Supply disruptions; Emergency procurement; Scenario analysis; Stackelberg game; dual sourcing; Competition; Resource allocation

\section{Introduction}

With the development of lean production and economic globalization, supply chains become more and more complexity and vulnerable. Manufacturers tend to reduce the number of suppliers so as to increase economies of scale to achieve cost reduction and convenient management. Under this circumstance, once one of suppliers cannot delivery for disruption, it is possible bring the huge loss to downstream manufacturers or distributors and the entire supply chain. Facing with the supply disruption of the fire on March 2000 at the Philips plant in Albuquerque, NM, Nokia seek proactively other emergency suppliers, gaining great market share, and Ericsson waited passively, losing huge market share. On October 2011, Apple MacBook Air's main supplier of metal chassis was ordered to suspend production for rectification by the local government because of environment destruction. These cases illustrate the necessary of contingent sourcing.

There has been a growing stream of literature on supply disruptions. C. Blome[1]study a review of the literature about supply disruption management , and list a detailed qualitative analysis. O. Tang [2] provides supplier faces detailed presentation risk factors and give some contingent sourcing. G. Burke and J. Carrillo [3] shows unless the supplier's capacity is greater than the product demand and buyer unable to obtain the differential benefit, single-sourcing is better than dual-souring. Wang et al.[4] hypothesis two suppliers are unstable, they have different cost structure and 
respectively independent. Supply chain is divided into four scenarios, and then he establishes the expected profit function, using the approximation method to obtain the optimal ordering quantity. H.Yu and Amy Z. Zeng [4] study that supplier homogeneity degree is higher, the dual sourcing in response to supply disruptions in terms of the effect more obvious, and the traditional multi-sourcing is conducive to promoting competition among suppliers, to obtain the lowest purchase price. K. Chen [6] study the buyers adjust the wholesale price retailers or give allowance for suppliers to cope with supply Disruptions. Fabian et al.[7] analysis the effect of correlation between supply and demand uncertainty on the optimal sourcing strategy. X. Li et al. [8] divide disruptions into common cause failure and supplier-specific incident, and explore dualsourcing strategies to mitigate supply disruption risk. J. Hou[9] comparative advantages and disadvantages of the backup supplier strategy and dual-sourcing. Tomlin [10] through the newsboy model to study the dual sourcing flexibility and reliability, and analyzed the influence factors of second suppliers use. W. Zhang [11] compare the risk of dual source and dual mixed source, analyze the dual sourcing strategy under the different disruption probability how to affect buyers expected profits. X. Li et al. [12] present optimal ordering mechanisms based on options contracts for a triadic supply chain. J. Chen [13] research an unreliable supplier and a backup supplier of capacity constraints, the buyer how to choose the order strategy. V. Babich[14] research how to select backup supplier when supplier face disruption risk.

Our study is also related to the literature on competing manufacturers exposed to supply disruptions. B. Shou et al.[15] study two competing supply chains face uncertainties supply chain, retailers with cournot competition to determine the optimal number ordered from suppliers, they make decisions from three different aspects: operational, design, and strategic. Supply chain coordination may not be favorable for the growth of the supply chain, which mainly depends on the degree of the supply risk. $X$. Zhou [16] study multiple competing manufacturers and a multi-retailer supply chain, firstly retailers to determine each manufacturer according to the contract from each manufacturer and its retention of profits the number of products procured, then analyzed as a leading manufacturer Stackelberg game party game balance. Li et al. [17] analysis retailers procurement strategy and vendor pricing strategy when supply risk, where the spot market as a completely reliable suppliers, retailers take sourcing in both centralized and decentralized procurement strategy. V. Babich[18]research suppliers exist in the period ahead of supply risk, as the passive side of Stackelberg game retailers how to develop supply strategies based on problems affecting the relationship between suppliers to buyers. Tang and Kouvelis[19] study supplier diversification benefits for two competing buyers, the authors conclude that buyers should never choose the same supplier, because the increased correlation between the delivered quantities leads to a decrease in the buyers' profits.

Most of these documents focus on procurement strategy under supply chain disruption, but few literatures involve the study of procurement strategy under competition and supply-side disruption, and literatures considering the capacity constrained factors are less and less. Some literatures about the dual sourcing strategy are better than the single sourcing and safety stock, but this strategy is always have a cost advantage has yet to be considered.

In this paper, we investigate contingent sourcing under supply disruption and competition using the Stackelberg game mode. We model the manufacturers to engage in a quantity competition. Firstly, we examine the manufacturer the optimal order quantity and their expected profit in different scenarios. Then we explore the impact of supply disruption and 
procurement time on optimal order quantity and manufacturers' expected profit. Finally, we analyze how to obtain the optimal cost advantage by dual sourcing strategy.

\section{Model Assumptions and Symbol Description}

\subsection{Model Assumptions}

In a single-period model, we consider the manufacturers' procurement strategy under supply disruption and competition as shown in Figure 1. There are two manufacturers A and B that procure critical components from two suppliers represented by 1 and 2 . Both A and B process these components into substitutable products, then sell them at the same price in the market. Supplier 1 is unreliable and cheap, supplier 2 is reliable and expensive, and supplier 2 has capacity limits. Manufacturer A applies a dual-sourcing strategy, mainly buys products at a unit cost of $c_{1}$ from supplier 1 at normal, but with supply disruption of supplier 1 , manufacturer A enables emergency order from supplier 2 at a unit cost of ${ }^{c_{3}}$. Manufacturer B uses a single-sourcing strategy, and therefore he only buys components at a unit cost of $c_{2}$ from supplier 2. We assume $c_{3}>c_{2}>c_{1}$.

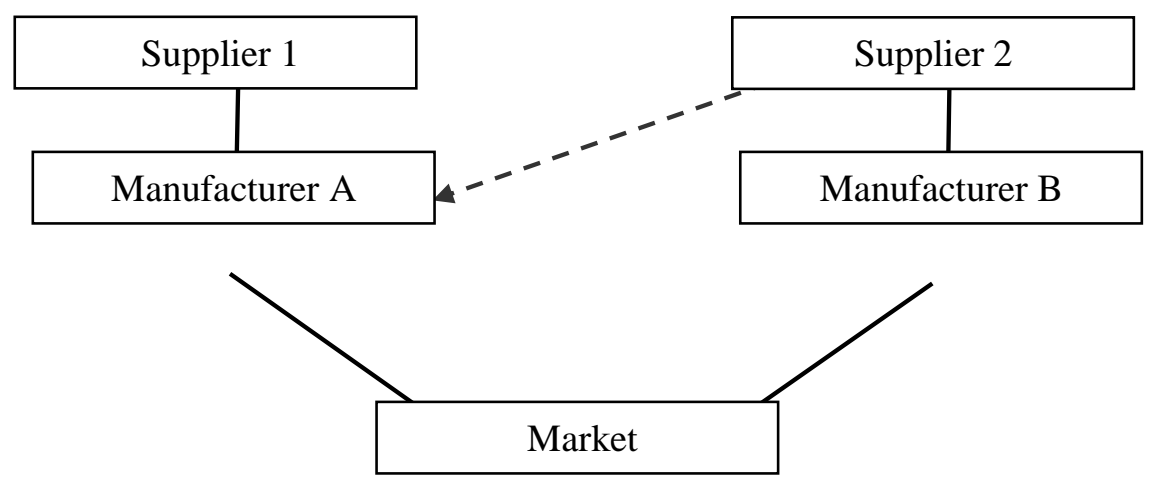

Figure1. Sourcing Model of Two Manufacturers

If supplier 1 defaults, A orders $Q_{E}$ from supplier 2. Supplier 2 cannot fully meet the delivery subject to capacity constraints. Due to capacity constraints, the proportion that

supplier 2 can be provided quantity accounts for $\beta$ of the total emergency order quantity that A need purchase. That is to say, emergency procurement quantity that the supplier 2 offers $\mathrm{A}$ is $\beta Q_{E}$.

\subsection{Symbol Description}

Model symbols are described in Table 1. 
Table1. Symbol Description

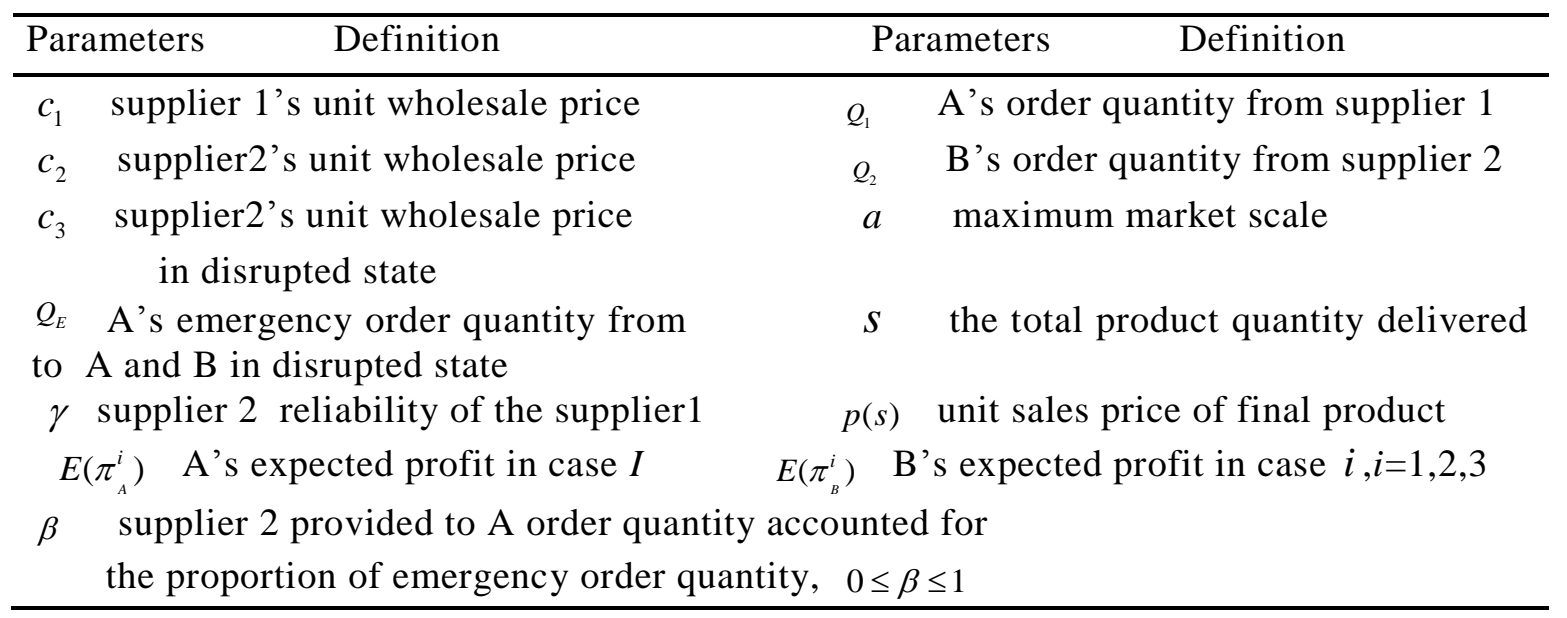

\section{Analysis of the Sourcing Strategy under Supply Disruption and Competition}

According to the occurrence of these event, there can be divided into three kinds of situation: A and B order at the same time, A orders first, or A orders last.

\subsection{Case 1}

The sequence of event in this case is shown in Figure 2.

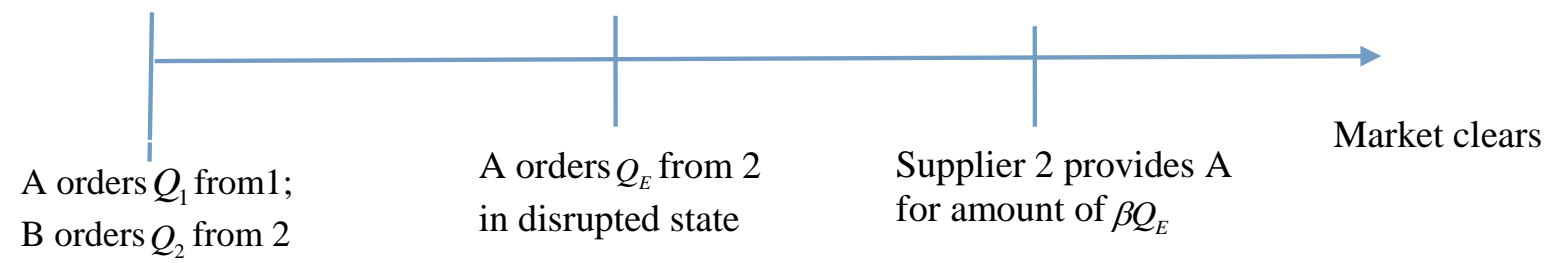

Figure2. Procurement Flow Chart in Case 1

As shown in Figure 2, A and B at the same time order $Q_{1}$ and $Q_{2}$ from suppliers 1 and 2, respectively. When supplier 1 defaults, A places an emergency order $Q_{E}$ from supplier 2 . Supplier 2 has capacity limits, so only provides A for $\beta Q_{E}$.

According to the Stackelberg equilibrium, $\mathrm{A}$ and $\mathrm{B}$ simultaneously order $Q_{1}$ and $Q_{2}, \mathrm{~A}$ and $\mathrm{B}$ both acting as the leaders. After supplier 1 defaults, A determines the emergency order quantity $Q_{E}$ based on the order quantity $Q_{1}$ and $Q_{2}$, this makes A as the follower. We use backward induction to obtain the equilibrium solution. We use the feedback function $q_{E}\left(Q_{1}, Q_{2}\right)$ to represent A's emergency order quantity $Q_{E}$.

When supplier 1 defaults, A's maximize profit is as follows,

$$
\max _{q_{E}}\left[\left(a-Q_{2}-Q_{e}-c_{3}\right) Q_{e}\right]
$$


By solving this, we obtain the best response function of A

$$
q_{E}\left(Q_{1}, Q_{2}\right)=\frac{a-Q_{2}-c_{3}}{2}
$$

We acquire A's emergency order quantity reaction function. Next we solve the Nash game between $\mathrm{A}$ and $\mathrm{B}$. As $\mathrm{A}$ and $\mathrm{B}$ order $Q_{1}$ and $Q_{2}$ simultaneously, we obtain A and B's expected profits maximization problems.

$$
\begin{aligned}
& \max _{Q_{1}}\left[\gamma\left(a-Q_{1}-Q_{2}-c_{1}\right) Q_{1}+(1-\gamma)\left(a-Q_{2}-\beta \cdot \frac{a-Q_{2}-c_{3}}{2}-c_{3}\right) \beta \frac{a-Q_{2}-c_{3}}{2}\right] \\
& \max _{Q_{2}}\left[\gamma\left(a-Q_{1}-Q_{2}-c_{2}\right) Q_{2}+(1-\gamma)\left(a-\beta \cdot \frac{a-Q_{2}-c_{3}}{2}-Q_{2}-c_{2}\right) Q_{2}\right]
\end{aligned}
$$

By solving this, we obtain the optimal order quantity $Q_{1}$ and $Q_{2}$.

$$
\begin{aligned}
Q_{1}^{1} & =\frac{-2 a-2 c_{2}+\beta a(1-\gamma)+\beta c_{3}(1-\gamma)+2(\gamma-1) \beta c_{1}+4 c_{1}}{2[2 \beta(1-\gamma)+\gamma-4]} \\
Q_{2}^{1} & =\frac{a r+a \beta-2 a-c_{1} r+2 c_{1}-r a \beta-(1-\gamma) \beta c_{3}}{2 \beta(1-\gamma)+\gamma-4}
\end{aligned}
$$

Inserting (6) into the objective function (2) yields the emergency order quantity.

$$
Q_{E}^{1}=\frac{a \beta-a \beta \gamma-2 a-c_{3} \beta+c_{3} \beta \gamma-c_{3} \gamma+4 c_{3}+c_{1} \gamma-2 c_{2}}{2[2 \beta(1-\gamma)+\gamma-4]}
$$

Then we obtain A and B's expected profits.

$$
\begin{aligned}
& E\left(\pi_{A}^{1}\right)=\left[\gamma\left(a-Q_{1}^{1}-Q_{2}^{1}-c_{1}\right) Q_{1}^{1}+(1-\gamma)\left(a-Q_{2}^{1}-\beta \cdot \frac{a-Q_{2}^{1}-c_{3}}{2}-c_{3}\right) \beta \frac{a-Q_{2}^{1}-c_{3}}{2}\right] \\
& E\left(\pi_{B}^{1}\right)=\left[\gamma\left(a-Q_{1}^{1}-Q_{2}^{1}-c_{2}\right) Q_{2}^{1}+(1-\gamma)\left(a-\beta \cdot \frac{a-Q_{2}^{1}-c_{3}}{2}-Q_{2}^{1}-c_{2}\right) Q_{2}^{1}\right]
\end{aligned}
$$

Proposition 1: $Q_{1}^{1}$ increases in $\gamma, \beta$ and $c_{2}$, decreases in $c_{1}$ and $c_{3} . Q_{2}^{1}$ increases in $c_{1}$ and $c_{3}$, decreases in $\gamma, \beta$ and $c_{2} . Q_{E}^{1}$ increases in $\gamma$, decreases in $c_{1}, c_{2}$ and $c_{3}$.

Proof: Solving the first-order of formula (5) and (6) yields

$$
\begin{aligned}
& \frac{\partial Q_{1}^{1}}{\partial c_{1}}=\frac{(\gamma-1) \beta+2}{2 \beta(1-\gamma)+\gamma-4}<0, \frac{\partial Q_{1}^{1}}{\partial c_{2}}=\frac{-2}{2 \beta(1-\gamma)+\gamma-4}>0, \frac{\partial Q_{1}^{1}}{\partial c_{3}}=\frac{\beta(1-\gamma)}{2[2 \beta(1-\gamma)+\gamma-4]}<0, \\
& \frac{\partial Q_{1}^{1}}{\partial \gamma}=\frac{-\beta a-\beta c_{3}+2 \beta c_{1}}{2[2 \beta(1-\gamma)+\gamma-4]}>0, \frac{\partial Q_{1}^{1}}{\partial \beta}=\frac{(1-\gamma)\left[\gamma\left(a+c_{3}-2 c_{1}\right)+4 c_{2}-4 c_{3}\right.}{2[2 \beta(1-\gamma)+\gamma-4]^{2}}>0 .
\end{aligned}
$$

Similarly, we can lead to the results for $Q_{2}^{1}$ and $Q_{E}^{1}$.

That is to say, when the cost of supplier 2 increases, supplier 1 has a higher cost advantage over supplier 2, so A from the supplier 1 order quantity will increase. When the cost of supplier 1 increase, manufacturer $\mathrm{A}$ has to bear the procurement cost will increase, it will also reduce the order quantity. To increase the reliability of supplier 1 , means that $\mathrm{A}$ is more advantage than B, with the increase of reliability, A purchases more and B buy less. 


\subsection{Case 2}

The sequence of event in this case is shown in Figure 3.

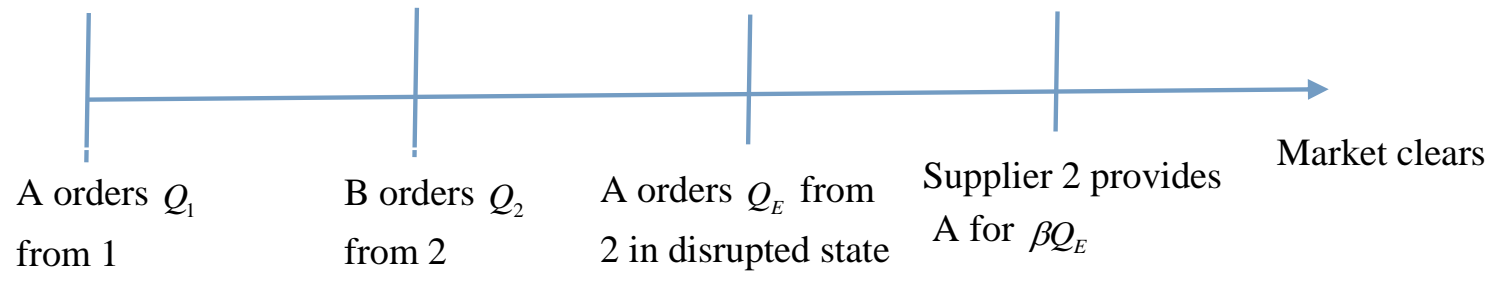

\section{Figure 3. Procurement Flow Chart in Case 2}

As shown in Figure 3, A first orders $Q_{1}$ from supplier 1, then B orders $Q_{2}$ from supplier 2. When supplier 1 defaults, A places an emergency order $Q_{E}$ from supplier 2. Supplier 2 has capacity limits, so provides A for $\beta Q_{E}$.

The case consists of two Stackelberg games. In the first Stackelberg game, A as the leader first orders, B as the follower then orders after the observation of A's behavior. In the second Stackelberg game, B first orders, and then A orders emergency quantity after observing B's behavior. Therefore, A's response order quantity is the feedback function $q_{E}\left(Q_{1}, Q_{2}\right)$. Thus, B's problem is

$$
\max _{Q_{2}}\left[\gamma\left(a-Q_{1}-Q_{2}-c_{1}\right) Q_{2}+(1-\gamma)\left(a-Q_{2}-\beta \cdot \frac{a-Q_{2}-c_{3}}{2}-c_{3}\right) Q_{2}\right]
$$

By solving this, we obtain the best response of $\mathrm{B}$

$$
q_{2}\left(Q_{1}\right)=\frac{a(2-\beta+\gamma \beta)+c_{3}(\beta-\gamma \beta)-2 c_{2}-2 \gamma Q_{1}}{2(\gamma \beta+2-\beta)}
$$

Using the first Stackelberg game yields A's maximizes expected profit

$$
\max _{Q_{1}}\left[\gamma\left(a-Q_{1}-q_{2}\left(Q_{1}\right)-c_{1}\right) Q_{1}+(1-\gamma)\left(a-\beta \cdot \frac{a-q_{2}\left(Q_{1}\right)-c_{3}}{2}-q_{2}\left(Q_{1}\right)-c_{3}\right) \beta \cdot \frac{a-q_{2}\left(Q_{1}\right)-c_{3}}{2}\right]
$$

By solving this, we obtain the optimal order quantity $Q_{1}$.

$$
Q_{1}^{2}=\frac{\left(a-2 c_{1}\right)(\gamma \beta+2-\beta)+c_{3}(\beta-\gamma \beta)-2 c_{1}}{2[3(\gamma \beta+2-\beta)-\gamma]}
$$

Inserting (13) into the objective functions (11) leads to the optimal order quantity $Q_{2}$.

$$
Q_{2}^{2}=\frac{[3(\gamma \beta+2-\beta)-\gamma]\left[c_{3}(\beta-\gamma \beta)-2 c_{1}+a(\gamma \beta+2-\beta)\right]-4 \gamma c_{1}(\gamma \beta+2-\beta)}{2(\gamma \beta+2-\beta)[3(\gamma \beta+2-\beta)-\gamma]}
$$

Inserting function (14) into the objective functions (2), then we obtain the emergency order quantity.

$$
Q_{E}^{2}=\frac{a-c_{3}}{2}-\frac{[3(\gamma \beta+2-\beta)-\gamma]\left[c_{3}(\beta-\gamma \beta)-2 c_{1}+a(\gamma \beta+2-\beta)\right]-4 \gamma c_{1}(\gamma \beta+2-\beta)}{4(\gamma \beta+2-\beta)[3(\gamma \beta+2-\beta)-\gamma]}
$$

Then A and B's expected profits are as follows. 


$$
\begin{gathered}
E\left(\pi_{A}^{2}\right)=\left[\gamma\left(a-Q_{1}^{2}-q_{2}\left(Q_{1}\right)-c_{1}\right) Q_{1}^{2}+(1-\gamma)\left(a-\beta \cdot \frac{a-q_{2}\left(Q_{1}\right)-c_{3}}{2}-q_{2}\left(Q_{1}\right)-c_{3}\right) \beta \cdot \frac{a-q_{2}\left(Q_{1}\right)-c_{3}}{2}\right] \\
E\left(\pi_{B}^{2}\right)=\left[\gamma\left(a-Q_{1}^{2}-Q_{2}^{2}-c_{1}\right) Q_{2}^{2}+(1-\gamma)\left(a-Q_{2}^{2}-\beta \cdot \frac{a-Q_{2}^{2}-c_{3}}{2}-c_{3}\right) Q_{2}^{2}\right]
\end{gathered}
$$

Proposition 2: $Q_{1}^{2}$ increases in $\gamma, \beta$ and $c_{2}$, decreases in $c_{1}$ and $c_{3}, Q_{2}^{2}$ increases in $c_{1}$ and $c_{3}$, decreases in $\gamma, \beta$ and $c_{2}, Q_{E}^{2}$ increases in $\gamma$, decreases in $c_{1}, c_{2}$ and $c_{3}$.

\subsection{Case 3}

The sequence of event in this case is shown in Figure 4.

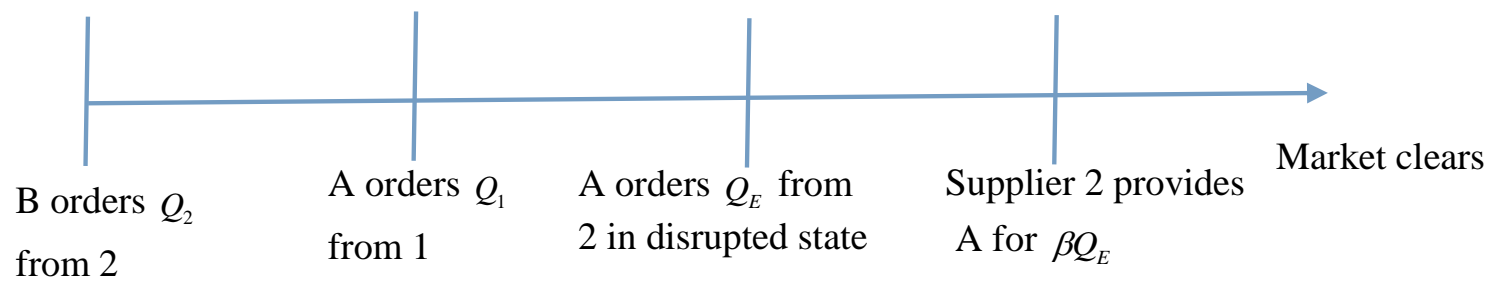

\section{Figure 4. Procurement Flow Chart in Case 3}

As shown in Figure 4, B first orders $Q_{2}$ from supplier 2, then A orders $Q_{1}$ from supplier 1. This is the first Stackelberg game. When supplier 1 defaults, A places an emergency order $Q_{E}$ from supplier 2. This is the second Stackelberg game. Supplier 2 has capacity limits, so provides $\mathrm{A}$ for $\beta Q_{E}$. Therefore, A's response order quantity is the feedback function $q_{E}\left(Q_{1}, Q_{2}\right)$ as given in (2). Thus, A's problem is

$$
\max _{Q_{1}}\left[\gamma\left(a-Q_{1}-Q_{2}-c_{1}\right) Q_{1}+(1-\gamma)\left(a-Q_{2}-\beta \cdot \frac{a-Q_{2}-c_{3}}{2}-c_{3}\right) \beta \frac{a-Q_{2}-c_{3}}{2}\right]
$$

By solving this, we obtain the best response of A.

$$
q_{1}\left(Q_{2}\right)=\frac{a-Q_{2}-c_{1}}{2}
$$

In the first stage of Stackelberg game, B is the leader order $Q_{2}$ from suppliers 2, and A orders $Q_{1}$ and $Q_{E}$ according to B's behavior. Therefore, according to (19) and (2) we obtain B's expected profit maximization problem.

$$
\max _{Q_{2}}\left[\gamma \frac{a-Q_{2}-c_{1}-2 c_{2}}{2} Q_{2}+(1-\gamma)\left(a-\beta \cdot \frac{a-Q_{2}-c_{3}}{2}-Q_{2}-c_{3}\right) Q_{2}\right]
$$

By solving this, we obtain the optimal order quantity $Q_{2}$.

$$
Q_{2}^{3}=\frac{-\gamma a+\gamma c_{1}+2 a-2 c_{2}-\beta(1-\gamma)\left(a-c_{3}\right)}{2-2(1-\gamma)(\beta-1)}
$$


Inserting (21) into the objective functions (19), then we obtains the optimal order quantity $Q_{1}$.

$$
Q_{1}^{3}=\frac{2\left(a-c_{1}\right)-2(1-\gamma)(\beta-1)\left(a-c_{1}\right)+\beta(1-\gamma)\left(a-c_{3}\right)+\gamma a-\gamma c_{1}-2 a+2 c_{2}}{4-4(1-\gamma)(\beta-1)}
$$

We insert (21) into the objective functions (2) to obtain

$$
Q_{e}^{3}=\frac{\gamma a-\gamma c_{1}+2 c_{2}-2 c_{3}+(1-\gamma)\left(a-c_{3}\right)(2-\beta)}{4-4(1-\gamma)(\beta-1)}
$$

Then we obtain A and B's expected profits.

$$
\begin{aligned}
& E\left(\pi_{A}\right)=\left[\gamma\left(a-Q_{1}^{3}-Q_{2}^{3}-c_{1}\right) Q_{1}^{3}+(1-\gamma)\left(a-Q_{2}^{3}-\beta \cdot \frac{a-Q_{2}^{3}-c_{3}}{2}-c_{3}\right) \beta \frac{a-Q_{2}^{3}-c_{3}}{2}\right] \\
& E\left(\pi_{B}\right)=\left[\gamma \frac{a-Q_{2}^{3}-c_{1}-2 c_{2}}{2} Q_{2}^{3}+(1-\gamma)\left(a-\beta \cdot \frac{a-Q_{2}^{3}-c_{3}}{2}-Q_{2}^{3}-c_{3}\right) Q_{2}^{3}\right]
\end{aligned}
$$

Proposition 3: $Q_{1}^{3}$ increases in $\beta$ and $c_{2}$, decreases in $c_{1}, \gamma$ and $c_{3}$. $Q_{2}^{3}$ Increases in $c_{1}, \gamma$ and $c_{3}$, decreases in $\beta$ and $c_{2} . Q_{E}^{3}$ Decreases in $c_{1}, c_{2}, \gamma$ and $c_{3}$.

Proposition 4: Priority ordering manufacturers have higher profits. A's expected profits satisfy $E\left(\pi_{A}^{2}\right)>E\left(\pi_{A}^{1}\right)>E\left(\pi_{A}^{3}\right)$. B's expected profits satisfy $E\left(\pi_{B}^{2}\right)<E\left(\pi_{B}^{1}\right)<E\left(\pi_{B}^{3}\right)$.

\section{Analysis of Numerical Example}

In this section, we analyze the impact of different parameters on the procurement strategy in three scenarios. We explore the effects of supplier costs, stability, and capacity constraints and other factors change on A and B's expected profit. Parameter assignments are shown in Table 2.

Table 2. Parameter Assignments

\begin{tabular}{c|c|c|c|c|c|c}
\hline Parameter & $c_{1}$ & $c_{2}$ & $c_{3}$ & $a$ & $\gamma$ & $\beta$ \\
\hline Values & 3 & 4 & 5 & 100 & 0.2 & 0.7 \\
\hline
\end{tabular}

\subsection{Impact of Supplier Costs, Capacity Limits and Reliability on Profit of A}

(1) Capacity limits $\beta$ 


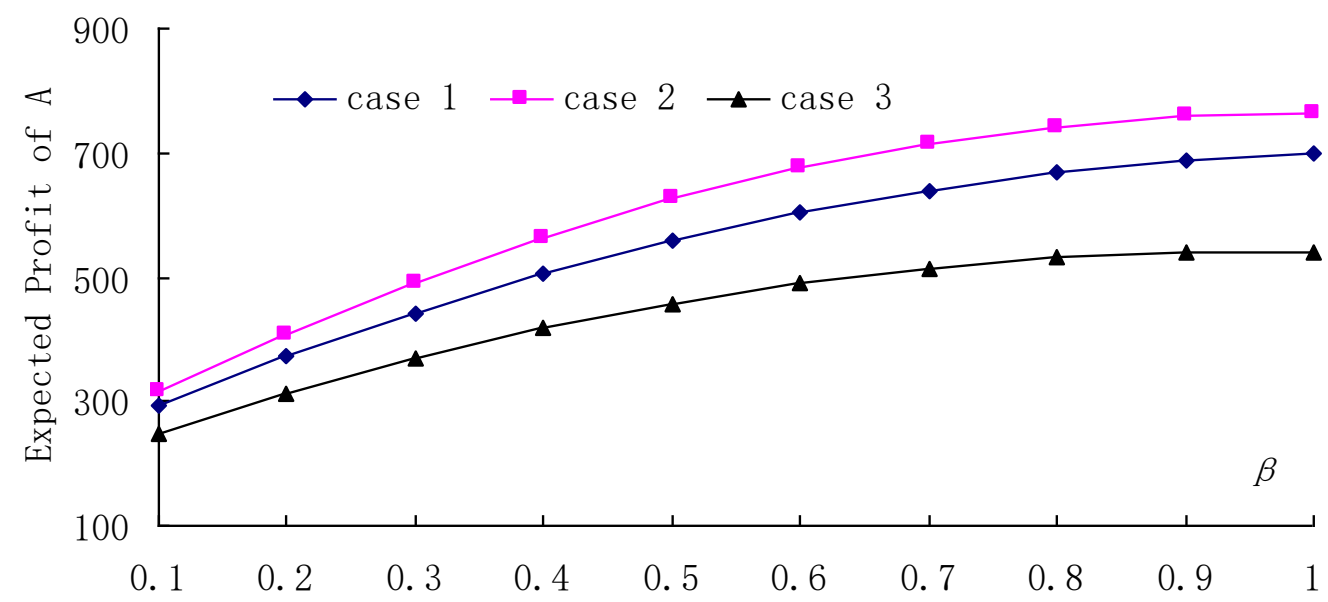

Figure 5. Variation of $E\left(\pi_{A}\right)$ with Respect to $\beta$ in Three Scenarios

As shown in Figure 5, with the increase of supplier 2's capacity limits $\beta$, manufacturer A's expected profit increases in three scenarios. When $\beta$ is increasing, the emergency order quantity $\beta Q_{E}$ is more close to optimal emergency order quantity $Q_{E}$, which makes A's expected profit maximization.

\section{(2) Supplier cost $c_{1}$}

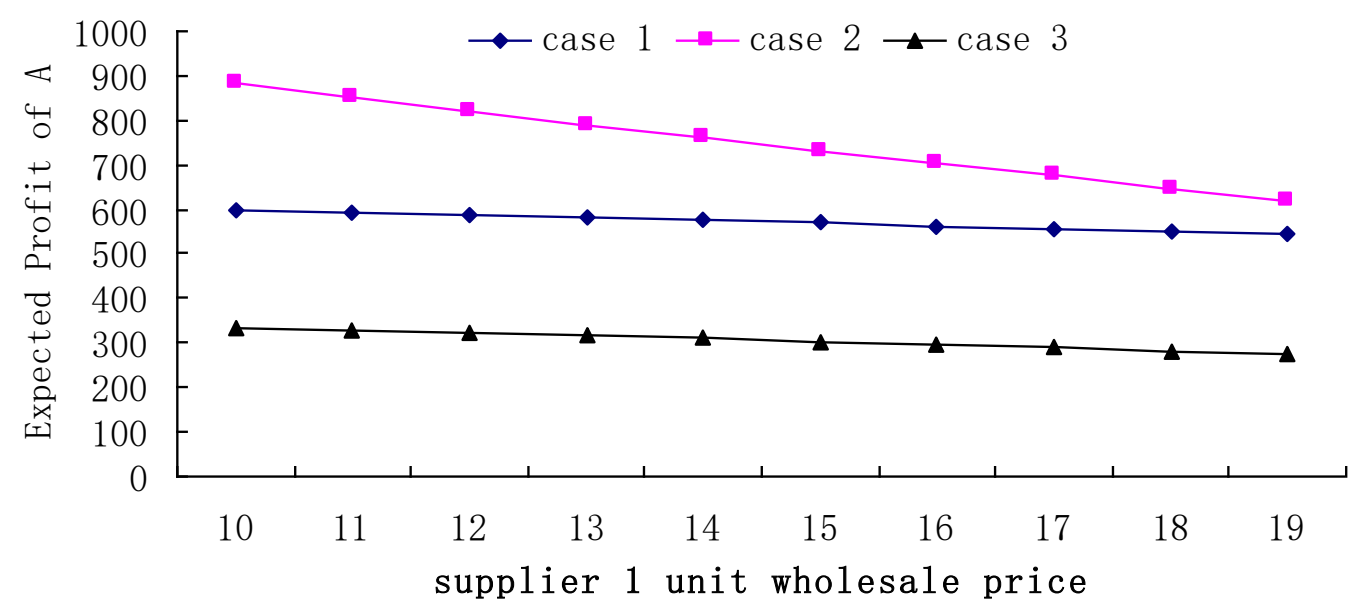

Figure 6. Variation of $E\left(\pi_{A}\right)$ with Respect to ${ }^{c_{1}}$ in Three Scenarios

As shown in Figure 6, the $E\left(\pi_{A}\right)$ decreases with an increase of $c_{1}$. This is because supplier 1 is the main supplier for $\mathrm{A}$, when $c_{1}$ increases, the cost of supplier 1 will increase, which makes A's expected profit decrease. 


\section{(3)Supplier reliability}

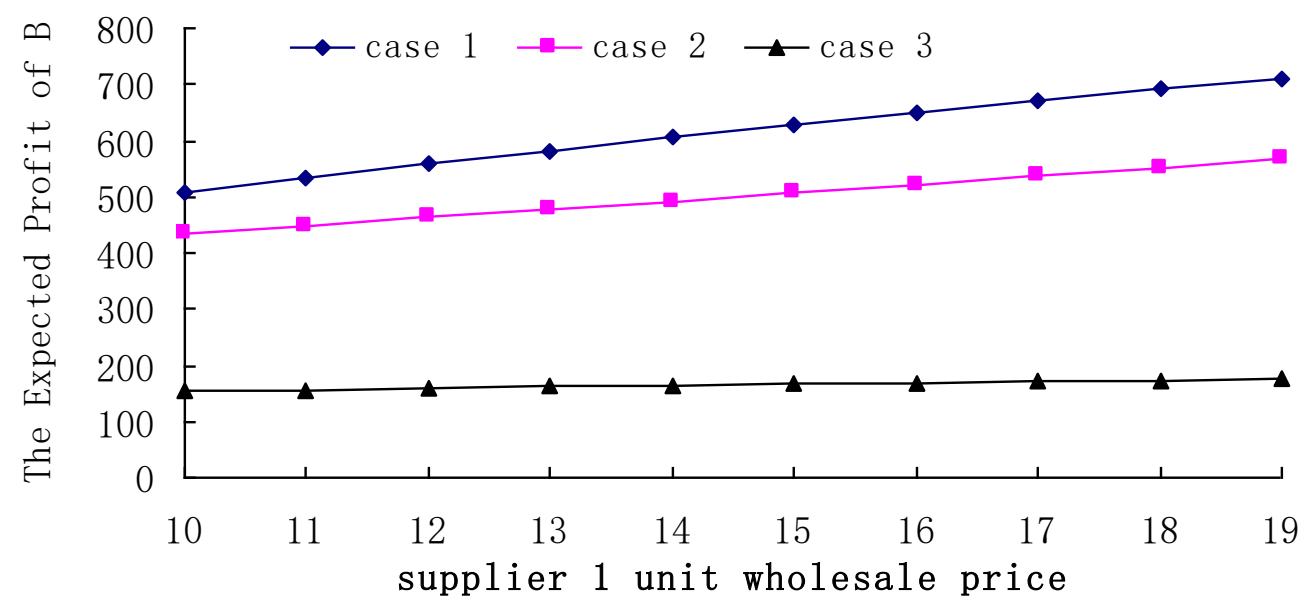

Figure 7. Variation of $E\left(\pi_{A}\right)$ with Respect to $\gamma$ in Three Scenarios

As shown in Figure 7, the $E\left(\pi_{A}\right)$ increases with an increase of supplier 1's reliability $\gamma$. This is because A has a cost advantage over B as supplier 1 is cheaper than 2. Then the expected profit of A's increases with $\gamma$.

\subsection{Impact of Supplier Costs, Capacity Limits and Reliability on Profit of B}

(1) Capacity limits $\beta$

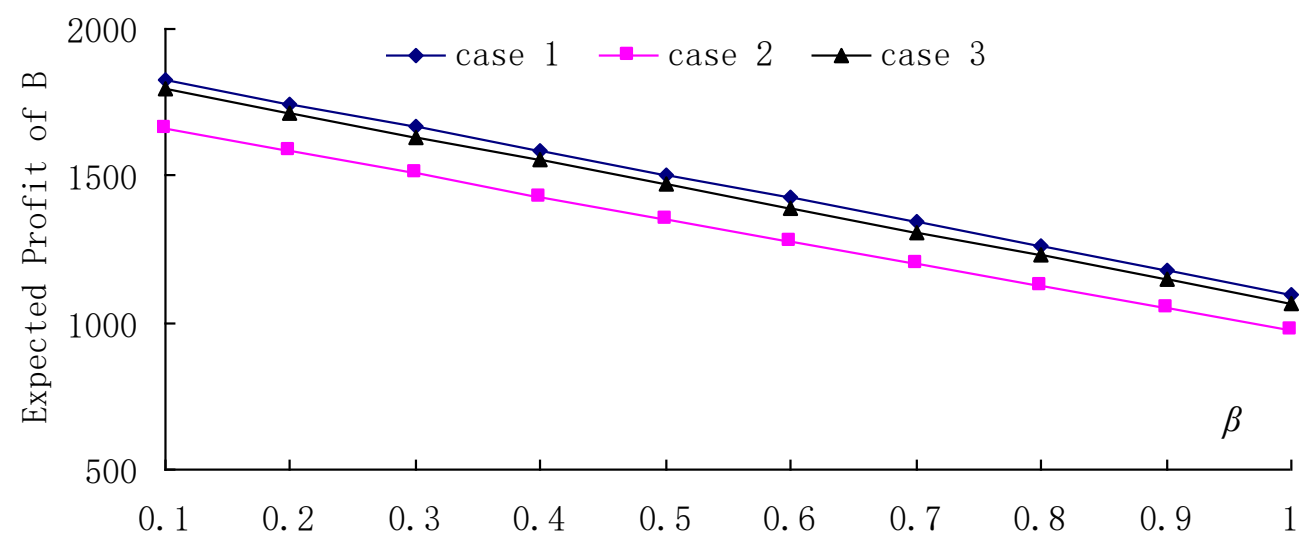

Figure 8. Variation of $E\left(\pi_{B}\right)$ with Respect to $\beta$ in Three Scenarios

As shown in Figure 7, the $E\left(\pi_{B}\right)$ decreases with an increase of supplier 2's capacity limit $\beta$. When $\beta$ increases, the emergency order quantity $\beta Q_{E}$ is more close to 
optimal emergency order quantity $Q_{E}$. According to $Q_{E}=\frac{a-Q_{2}-c_{3}}{2}, \beta Q_{E}$ and $Q_{2}$ is negative correlation, then manufacturers B's expected profit decreases with an increase of $\beta$.

\section{(2)Supplier cost $c_{2}$}

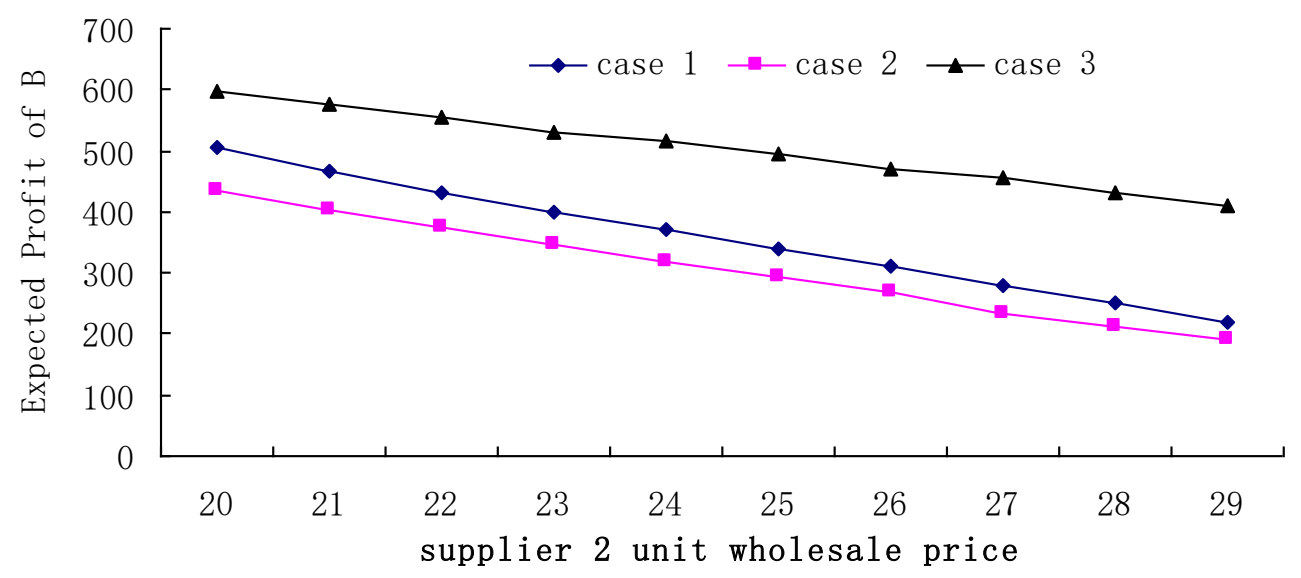

Figure 9. Variation of $E\left(\pi_{B}\right)$ with Respect to $c_{2}$ in Three Scenarios

As shown in Figure 9, the $E\left(\pi_{B}\right)$ decreases with an increase in $c_{2}$. This is because supplier 2 is the only supplier of $\mathrm{B}$, when $c_{2}$ increases, the cost of supplier 2 increases, which makes B's, expected profit decrease.

\section{(3)Supplier Reliability $\gamma$}

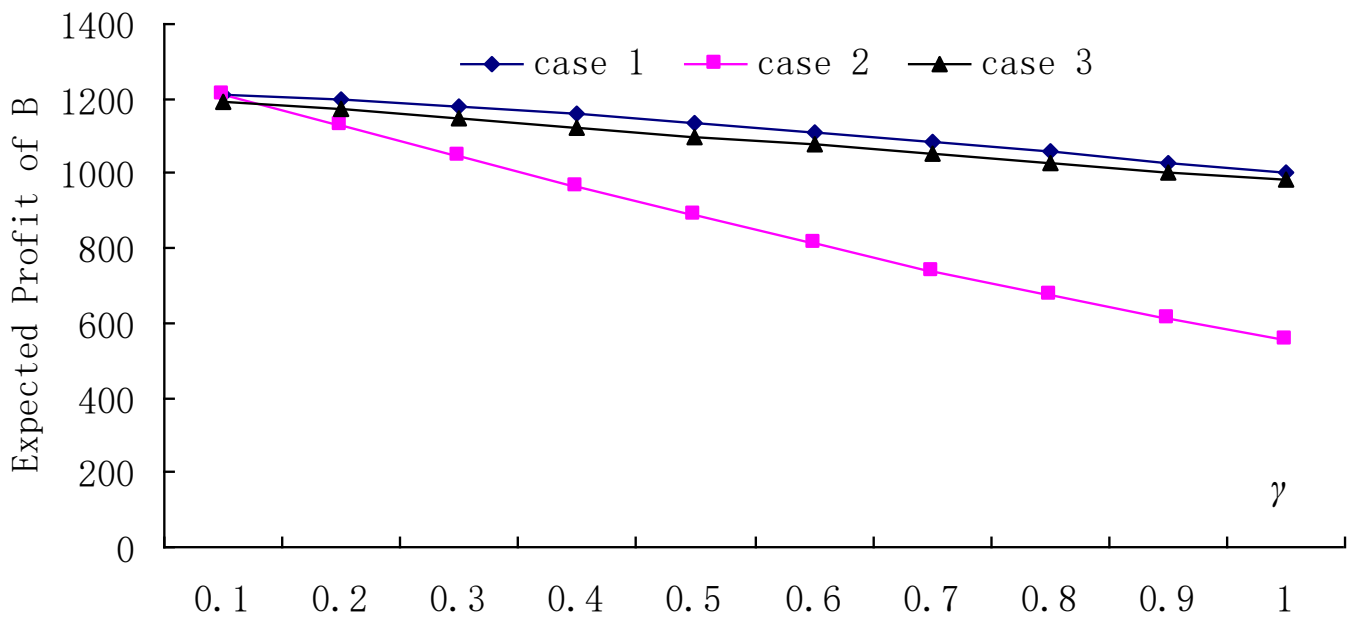

Figure10. Variation of $E\left(\pi_{B}\right)$ with Respect to $\gamma$ in Three Scenarios 
As shown in Figure $10, E\left(\pi_{B}\right)$ decreases with an increase of supplier 1's reliability $\gamma$. Due to $c_{1}<c_{2}$, when supplier 1 's disruption risk is small, A has a cost advantage over B, and then the expected profit of B decreases with $\gamma$.

\subsection{Expected Profits of A and B under Different Disruption Probability}

This section compares the expected profit value of manufacturer A and B. In comparison of expected profits, we adopt the profits difference between A and B values $E\left(\pi_{A}\right)-E\left(\pi_{B}\right)$ for analysis

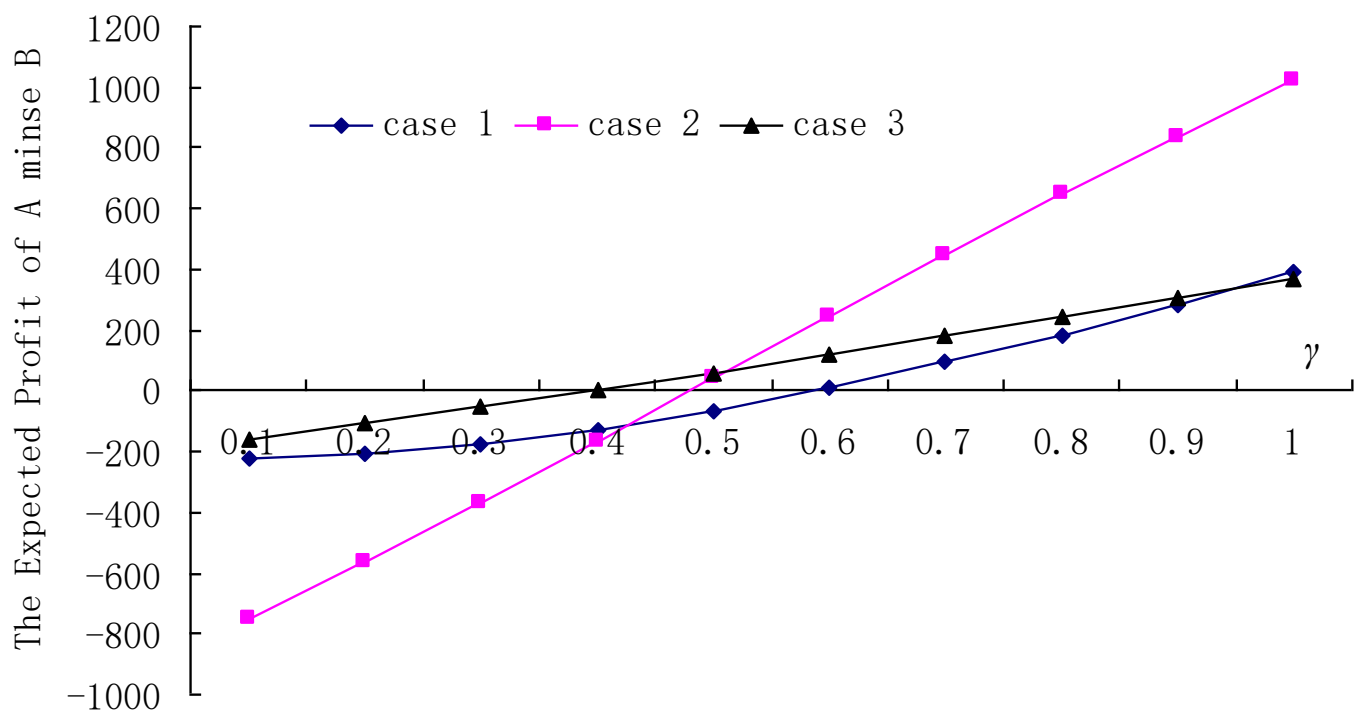

\section{Figure11. Variation of $E\left(\pi_{A}\right)-E\left(\pi_{B}\right)$ with Respect to $\gamma$ in Three Scenarios}

As shown in Figure $11, E\left(\pi_{A}\right)-E\left(\pi_{B}\right)$ increases with an increase in supplier 1 reliability $\gamma$. That is to say when the supplier 1 reliability is high, $E\left(\pi_{A}\right)-E\left(\pi_{B}\right)$ is larger, dual-sourcing is better than single-sourcing. And when the supplier 1 's reliability is lower, $E\left(\pi_{A}\right)-E\left(\pi_{B}\right)$ is negative, that is single-sourcing is better than dual-sourcing.

\section{Conclusions}

This paper mainly investigates single sourcing and dual sourcing strategy based on the market competition and supply disruption. We obtain that the manufacturer the optimal order quantity and their expected profit in different scenarios. Further studies show supply disruption and procurement time affect the manufacturer's purchasing decisions. Since the manufacturers cannot control the supply disruption, manufacturers should choose the proper order strategies to mitigate the losses caused by the interruption of supply.

(1) The dual sourcing strategy has a cost advantage over single source procurement, but studies show that dual-souring is not completely superior to single-sourcing. Dual 
sourcing cost advantage depends on cheaper supplier's reliability. When the stability of supplier 1 is higher, the cost advantage will be significant, the dual sourcing strategy is better than the single source strategy.

(2) Priority ordering manufacturers have higher profits. Manufacturer B using singlesourcing obtain the maximum profit when he places the order before his competitor. In the same way, using dual sourcing, the profit of manufacturer $\mathrm{A}$ is maximal when he places the order before his competitor.

(3) There are other avenues to extend this article. First, based on the manufacturer's profit, we can examine the entire supply chain profits. Second, we can investigate limited supplier 1's capacity. Finally, our framework can be extended to consider more qualified suppliers.

\section{Acknowledgements}

This work is supported by the National Social Science Fund of China under Grant No. 12CGL042, the National Natural Science Fund of China under Grant No. 71372122, 71402158 and 71272122 . The authors also gratefully acknowledge the helpful comments and suggestions of the reviewers, which have improved the presentation.

\section{References}

[1] C. Blame, M. Henke, "Supply chain risk: a handbook of assessment, management and performance", Springer-Verlag New York Incorporation, (2009).

[2] O. Tang, S. Nurmaya, "Identifying risk issues and research advancements in supply chain risk management", International Journal of Production Economics, no. 133, (2011), pp. 25-34.

[3] G. Burke, J. Carrillo, A. Vakharia, "Single versus multiple supplier sourcing strategies", European Journal of Operational Research, vol. 182, no. 1, (2007), pp. 95-112.

[4] W. Wang, "The effect on optimal ordering quantity under disruption risk of two supplier", PhD Thesis of Taiwan University, (2011).

[5] H. Yu, Z. Amy, L. Zhao, "Single or dual sourcing: decision-making in the presence of supply chain disruption risks", OMEGA-International Journal of Management Science, no.4, (2009), pp. 788-800.

[6] K. Chen, P. Zhuang, "Disruption management for a dominant retailer with constant demand-stimulating service cost", Computers \& Industrial Engineering, (2011), pp. 936-946.

[7] F. J. Sting, A. Huchzermeier, "Dual sourcing: responsive hedging against correlated supply and demand uncertainty”, Naval Research Logistics, vol. 59, no. 1, (2012), pp. 69-89.

[8] X. Li, J. Ji, S. Wang, "Coordination and optimization of dual sourcing under supply disruptions", Journal of Industrial Engineering and Engineering Management, vol. 28, no. 3, (2014), pp.141-147.

[9] B. Tomlin, Y. Wang, "On the value of mix flexibility and dual sourcing in unreliable newsvendor networks", Manufacturing \& Service Operations Management, vol. 7, no. 1, (2005), pp.37-57.

[10] J. Hou, Z. Amy, L. Zhao, "Coordination with a backup supplier through buy-back contract under supply disruption", Transportation Research Part E, vol. 48, no. 5, (2010), pp. 340-347.

[11] W. Zhang, "Analysis on supply emergency management based on dual source", Journal of Shanghai Jiao Tong University, vol. 47, no. 3, (2013), pp. 454-458.

[12] X. Li, J. Ji, S. Wang, "Performance analysis of backup supplier for supply disruptions with stochastic demand", Operations Research and Management Science, vol. 22, no. 4, (2013), pp. 42-49.

[13] J. Chen, X. Zhao, Y. Zhou, "A periodic-review inventory system with a capacitated backup supplier for mitigating supply disruptions", European Journal of Operational Research,vol. 219, no. 2, (2012), pp.312323.

[14] V. Babich, "Vulnerable options in supply chains: effects of supplier competition", Naval Research Logistics, vol.53, no. 7, (2006), pp. 656-673.

[15] B. Shou, J. Huang, Z. Li, "Managing supply uncertainty under chain-to-chain competition", working paper, (2009).

[16] X. Zhou, Y. Zhao, W. Yin, "Purchasing optimization based on revenue-sharing contracts under many-to-one supply chain structure", Computer Integrated Manufacturing Systems, no. 11, (2009), pp. 2147-2152.

[17] J. Li, S. Wang, T. E Cheng. "Competition and cooperation in a single-retailer two-supplier supply chain with supply disruption”, International Journal of Production Economics, vol. 124, no. 1, (2010), pp. 137-150. 
[18] V. Babich, N. Apostolos, H. Ritchken, "Competition and diversification effects in supply chains with supplier default risk", Manufacturing and service operations management, vol. 9, no. 2, (2007), pp. 123-146.

[19] S. Tang, P. Kouvelis, "Supplier diversification strategies in the presence of yield uncertainty and buyer competition", Manufacturing and Service Operations Management, vol. 13, no. 4, (2011), pp. 439-451.

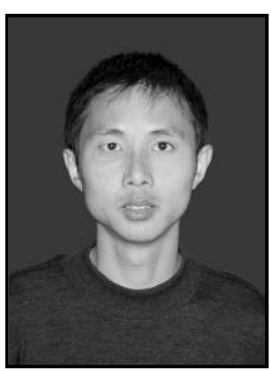

Xinjun Li. Xinjun $\mathrm{Li}$ is an associate professor in the school of economics and management at Yantai University, China. He received MS in management science and engineering from Tianjin University (2004) and $\mathrm{PhD}$ in operations management from Southeast University (2007). He does postdoctor research twice at Shanghai Jiaotong University and Dalian University of Technology respectively. His current research interests mainly focus on supply disruption and operation management. His research is published in leading scientific journals such as "Operations Research and Management Science", "Journal of Industrial Engineering and Engineering Management", "Control and Decision" and "Journal of Mechanical Engineering".

Xiaonan Zhang Xiaonan Zhang is a master in logistics management

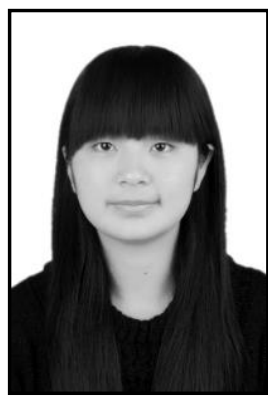
from the school of economics and management at Yantai University. She received her bachelor's degree in E-commerce from Taiyuan University of Science and Technology in 2012. His research direction is emergency management and supply chain management. 